The reasons for the long delay in exploiting induced mutation are, in part, apparent from this volume in which are recorded the contributions made to a specialist meeting by twenty-six workers who are pre-eminent in the field. Five contributions from a total of seventeen deal primarily with the techniques rather than with the results of mutation breeding. The delayed use of mutation breeding arose from the difficulty of resolving some of the practical problems discussed in these papers. These concern the type of mutagen to use, the dose and the stage of the life eycle of the plant to treat. When seeds are treated it is necessary to know what conditions of water content, temperature and oxygen concentration should be maintained before, during and after the treatment. Finally, problems are posed by the difficulty of recognizing beneficial genetic changes in quantitative characters.

Enough is now known about all these problems for mutation breeding to be used in practice. A crucial step in attaining this position resulted from the addition of chemical mutagens to the physical agencies previously employed, and it is useful to have, in this book, a contribution from $\mathrm{H}$. Heslot, who has played a significant part in the study of chemical mutagenesis.

Eight of the papers concerned with the results of mutation breeding on particular crops deal with barley, four with wheat and one each with maize, rice and peas. Substantial evidence is provided of the improvements that can follow the application of mutation breeding. The most dramatic example, by Nilan, describes the results of the treatment, with diethyl sulphate, of the barley variety "Alpine" which is cultivated in the State of Washington. In 1966, five years after the treatment, a mutant product was released to growers as a variety to replace "Alpine". During three years of trials this mutant yielded from 109 per cent to 119 per cent of "Alpine", depending on fertility conditions. It is 6 in. shorter than "Alpine" with much better resistance to lodging and has an increase of more than one spike on each plant. By any standards this is a remarkable piece of plant breeding - the short time taken between the first manipulation and the release of the variety represents a considerable achievement.

Mutation breeding can therefore produce the goods, and consequently every plant breeder must consider his task and decide whether his aims can more easily be attained by the manipulation of pre-existing variation or by the induction of new variation. In reaching a decision many factors must be considered, among which will be the potentialities of mutation breeding. The assessment of these potentialities will be aided by this book, and particularly by the scientific recommendations formulated by the panel whose meeting it records.

\section{Ralph Riley}

\section{MATERIALS ASSESSED}

\section{Nondestructive Testing}

By Warren J. McGonnagle. Second edition. Pp. xi +455. (New York and London: Gordon and Breach, 1966. Distributed in the United Kingdom by Blackie and Sons, Ltd.) $200 s$.

This (undated) edition is deseribed as the second; the first appeared in 1961. There is no special preface, so the changes made in the new edition are not apparent. What is clear is that no reference has been made to any work published since the first edition, so that the book effectively states the position in the various subjects reviewed as it stood about 1960. Much of the detail is thus outdated, and the reproduction of, for example, electronic circuits of 1957 vintage is frankly a waste of effort.

The book covers all the important techniques: visual; liquid penetrants; thermal; X-ray radiography; gamma radiography; ultrasonies; damping; magnetic; and electrical, with special emphasis on eddy currents. It also deals specially with thickness measurements. 'There is a lot of good material in it, and it is an admirable text for someone seeking a way into the subject, but a very different text can be written to-day in the light of the great amount of research and development undertaken in this field in the past seven or eight years. Both the instrumentation aspects and the materials interpretations (for example, the influence of structural features in metals on the absorption of energy) have been strongly advanced, and it is regrettable that the opportunity was not taken to comb out the out-dated parts of the text and incorporate some new additions.

It seems hard to have to follow up such comments with criticism of another kind. The fact that the book is not very elegantly produced is not in itself a serious fault, but the reproduction of photographs on totally unsuitable paper is. The reason why some of the figures appear at all is a mystery, and in the cases where a good photograph is the best way to illustrate a point, the result is frankly lamentable. This is a terribly expensive ten-pounds-worth.

A. J. KENNEDY

\section{AUTOMATED LIBRARIES}

Brasenose Conference on the Automation of Libraries Edited by John Harrison and Peter Laslett. (Proceedings of the Anglo-American Conference on the Mechanization of Library Services, held at Oxford under the Chairmanship of Sir Frank Francis and sponsored by the Old Dominion Foundation of New York, June 30-July 3. 1966.) Pp. xv +173 . (London and Chicago: Mansell Information/Publishing, Ltd., 1967.) 45s.; $\$ 6.50$.

For several years now there have been studies of the application of computers to library processes and services, and enough work has been carried out to provide a reasonable body of expertise in this field. It was timely, therefore, that in mid-1966, thanks to the generosity of the Old Dominion Foundation of New York, an AngloAmerican Conference on the Automation of Libraries was held in Oxford.

The proceedings of the conference provide a useful progress report on a cross section of American work with much emphasis on the application of computers to cataloguing problems rather than to other equally fundamental problems of library management. Perhaps the most interesting paper is that describing the plans-now in operation--for a pilot study on the distribution of machine readable cataloguing data (Project MARC). There are two important contributions from Britain. The first is a joint paper from the British Museum, the Bodleian Library and Cambridge University Library which hints at the possibility of co-operative cataloguing. The second contribution is perhaps of greater importance for most librarians in Britain and is a paper on the plans of the British National Bibliography to produce a machine readable catalogue entry for every British book at the same time as, or even before, its publication. It seems a pity, however, that there is no account in the proceedings of work such as that carried out at the Universities of Southampton and Newcastle and at the Atomic Weapons Research Establishment, Aldermaston. The editors state that it was for the most part a matter of the American delegation expounding and the British listening and learning. Even at this early stage it is doubtful whether we in Britain need take quite such a humble view of our own activities, and it is to be hoped that this conference is but the precursor of others at which a more representative contingent from the British school can in turn offer their experience to their American colleagues.
H. T. Hookway 